\title{
EFFECTS OF CAPTIVITY ON THERMOREGULATION AND METABOLISM IN ARTIBEUS JAMAICENSIS (CHIROPTERA: PHYLLOSTOMATIDAE)
}

\author{
Eugene H. Studier and Don E. Wilson \\ Department of Rinlngy. Iniversity of Michigan-Flint, Flint, MI 48503, I S A and \\ National Fish and Wildlife Laboratory, U.S. Fish and Wildlife Service, \\ National Museum of Natural History, Washington, D.C. 20560, U.S.A.
}

(Received 7 March 1978)

\begin{abstract}
In the Jamaican fig-eating bat, Artibeus jamaicensis, oxygen consumption $10 \mathrm{C}$ in $\mathrm{cm}^{3} / \mathrm{g}$ per $\mathrm{hr}$ ) and deep body temperature $(T b$ in $\mathrm{C}$ ) are significantly related to ambient temperature ( $T a$ in C) and length of time in captivity, but not to the direction (low to high or high to low) of Ta change.

2. $\mathrm{OC}$ and $T b$ levels as functions of $T a$ rapidly change from those characteristic of a non-homeothermic endotherm on the day of capture to values characteristic of a homeothermic endotherm within 3-6 days in captivity.

3. Jamaican fig-eating bats examined within $12 \mathrm{hr}$ of capture were physiologically distinct from individuals of this species kept briefly ( 3 days) in captivity.

4. Bats tested within $12 \mathrm{hr}$ of capture at Tas of 30 and $25^{\circ} \mathrm{C}$ required $1 / 3$ and $2 / 3$ less metabolic encrgy, respectively, than bats maintained bricfly in captivity.
\end{abstract}

\section{INTRODUCTION}

For many neotropical bats the relationship of thermoregulation and metabolism as functions of ambient temperature remains unclear [compare $\mathrm{McNab}$ (1969) with Studier \& Wilson (1970)]. McNab (1969) found most neotropical species he tested, including Artibeus jamaicensis, to be homeothermic (constant deep body temperature) endotherms. In contrast, Studier \& Wilson (1970) found many neotropical species, including A. jamaicensis and other species studied by McNab (1969), to be highly variable in thermoregulatory capabilities, with most species showing patterns characteristic of non-homeothermic endotherms. Although these different patterns may result from genetic differences between populations of the species tested, they may reflect different methodological approaches by the investigators. Studier \& Wilson (1970) usually tested their bats with $12 \mathrm{hr}$ after capture, but McNab (1969) maintained his frugivorous bats in the laboratory for periods of up to 2 weeks before testing them. Furthermore, McNab (1969) apparently initially exposed his bats to a constant low ambient temperature $(T a)$ followed hy higher Tas, whereas Studier \& Wilson (1970) started with a high $T a$ followed by lower Tas. In an attempt to explain these opposing results, oxygen consumption (OC) and deep body temperature $(T h)$ as functions of $T a$, time in captivity, and the directions of $\mathrm{Ta}$ change. were determined in Artibeus jamaicensis.

\section{MATERIALS AND METHODS}

All bats were mist-netted at night on Barro Colorado Island, Panama Canal Zone; four males and one female A. jamaicensis on 4 July 1977 at Lutz Creek, and three males and two females on 5 July 1977 at marker 11 on Barbour Trail. These bats were returned to the laboratory, caged (each group of five in hardware cloth cages of $25 \times 23 \times 38 \mathrm{~cm}$ ) and provided with water and food (hananas and figs) which were readily taken. Cages were covered to allow limited lighting throughout the entire period of confinement. The morning after capture (time in captivity about $12 \mathrm{hr}$, at approximately $0800 \mathrm{hr}$, bats were weighed and placed in metabolism chambers. Methods for determination of $\mathrm{OC}$ and $T b$ were essentially identical to those described by Studier \& O'Farrell (1972) except that a Beckman Fieldlab (Polarographic) Oxygen Analyzer was used and air flowing through the entire system was not dried but was kept at ambient relative humidity. Bats captured on 4 July were exposed to an initial $\mathrm{Ta}$ of $30^{\mathrm{C}} \mathrm{C}$ on 5 , 8 and 11 July and were allowed to equilibrate within the system until $T b$ and $O C$ stabilized (at least $1.5 \mathrm{hr}$ ), at which time $T b, O C$ and chamber temperature were recorded and $\mathrm{Ta}$ was lowered to $25^{\circ} \mathrm{C}$. Bats were allowed to equilibrate to the new $T a$, and $T b, O C$ and chamber temperatures again were recorded. On 8 and $11 \mathrm{July}, T a$ was further lowered to $20^{\circ} \mathrm{C}$ and readings were taken a third time. The bats caught on 4 July thus comprised the high to low group. Bats caught the night of 5 July represented the low to high group, and were tested on 6,9 and 12 July as previously described, except that on 6 July bats were first exposed to $25^{\circ} \mathrm{C}$, allowed to equilibrate, and readings were taken. Ambient temperature was raised to $30 \mathrm{C}$ for a second set of readings. On 9 and $12 \mathrm{July}$, these bats were first exposed to a $T a$ of $20^{\circ} \mathrm{C}$, followed by later exposure to $25^{\circ} \mathrm{C}$. and finally to $30^{\circ} \mathrm{C}$. The time of initial testing for each group representer about $12 \mathrm{hr}$ of captivity, and is hereafter referred to as day $0:$ the second and third testing of each group thus was done on days 3 and 6 . After the final day of testing, all bats were released at their original capture sites.

Although one female from the low to high group died of unknown causes in captivity, all captive bats ate readily and exhibited no appreciable weight change. Mean weights on days 0,3 and 6 were $48.7,48.1$ and $49.0 \mathrm{~g}$, respectively. Originally we intended to examine two groups of five bats each at Tas of 30.25 and $20 \mathrm{C}$; however, on day 0 the $T b s$ of several individuals in the high to low group dropped markedly at $25^{\circ} \mathrm{C}$ and we decided that exposure to a $T a$ 
of $20 \mathrm{C}$ might result in the death of some bats and would obviously prevent further testing on days 3 and 6 . To obtain equal cell sizes for the ANOVA. the data set for one of the five bats in the high to low group was randomly selected and discarded. A multiple factor ANOVA ISokal \& Rohlf, 1969) was performed on data from two groups of four bats each with direction of Ta change (low to high and high to low), day of testing (davs 0,3 and 6 ), and $T a(25$ and $30 C)$ as independent variables. and $O C$ and $T h$ as dependent variables. Statistical significance was sel at $P<0.025$

\section{RESLLTS AND DISCLSSION}

Results of the ANOVA are condensed in Table 1. Both $T a$ and time in captivity significantly affect $O C$ and $T h$, whereas the direction of $T a$ change does not. Additionally, $O C$ is significantly related to the interaction of $T a$ and days in captivity. This significant interaction means that regressions of $O C$ on $T a$ change (increase) with days of captivity, i.e. regression slopes (conductance) are significantly affected by length of captivity. Most noteworthy is that both OC and $T h$ increase significantly with days of captivity, thus the bats exhibit metabolic patterns characteristic of a non-homeothermic endotherm at day 0 , but those of a homeothermic endotherm by day 3. This phenomenon may be readily visualized by inspection of Figs 1 and 2. This "captivity effect" probably accounts for the dicholomy between our previous data (Studier \& Wilson, 1970) and those of McNab (1969) for A. jamaicensis. The divergent data on other neotropical frugivorous bats in these two studies may also be explained by a "captivity effect" as would the similarities in the data on neotropical insectivores like Pteronotus. McNab (1969) tested Pteronotus soon after capture, after discovering that these bats would not feed in captivity, and obtained thermoregulatory data comparable to ours (Studier \& Wilson, 1970). The length of time in captivity may also explain the conflicting thermoregulatory and metabolic data reported by Stones \& Wiebers (1967) and Studier \& O'Farrell (1972) for Myotis lucifugus. The former authors studied captive bats and found them to be homeothermic endotherms, whereas the latter authors

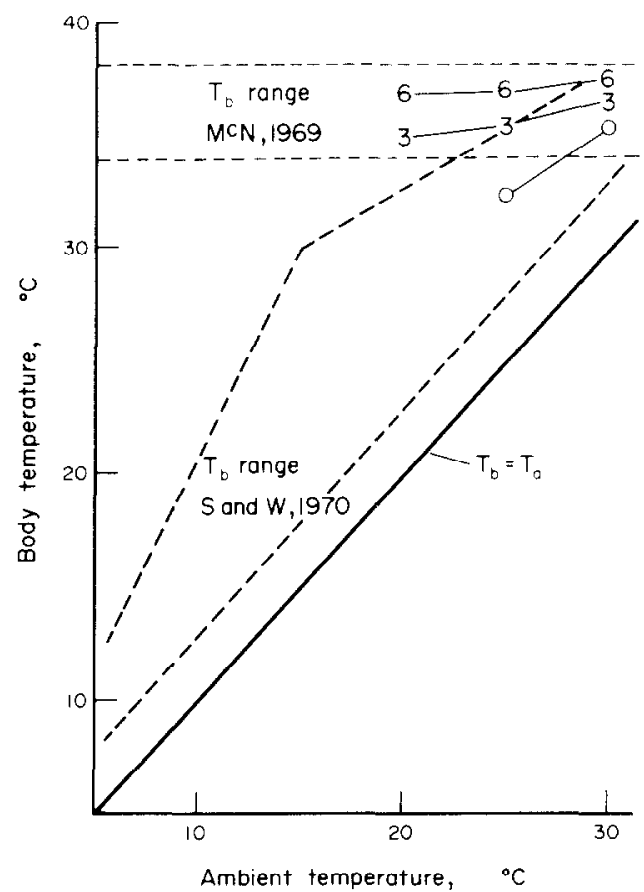

Fig. 1. The relationship of body temperature to ambient temperature in Artibeus jamaicensis. Dotted lines represent the ranges of previously reported data for this species by McNab (1969) and dashed lines the ranges from Studier $\&$ Wilson (1970). Mean body temperatures are shown for bats tested after 0.3 and 6 days in captivity.

studied freshly caught individuals and found them to be highly variable in respect to thermoregulatory performance and metabolism. The "captivity effect" may well also resolve other conflicting data on thermoregulatory activities and metabolism in other small mammals. A massive literature is devoted to thermoregulation in Perombscus leucopus (see Gaertner et al.. 1973: Hill, 1977) where conflicting data may be the result of time in captivity before testing. That season. reproductive condition. habitat selection and grouping may significantly affect metabolic and thermo-

Table 1. ANOVA of relationships of oxygen consumption and deep body temperature to ambient temperature (Tas of 25 and $30 \mathrm{C}$ ). direction of Ta change, days in captivity $(0,3$ and 6$)$. and interactions in captive Artibeus jamaicensis

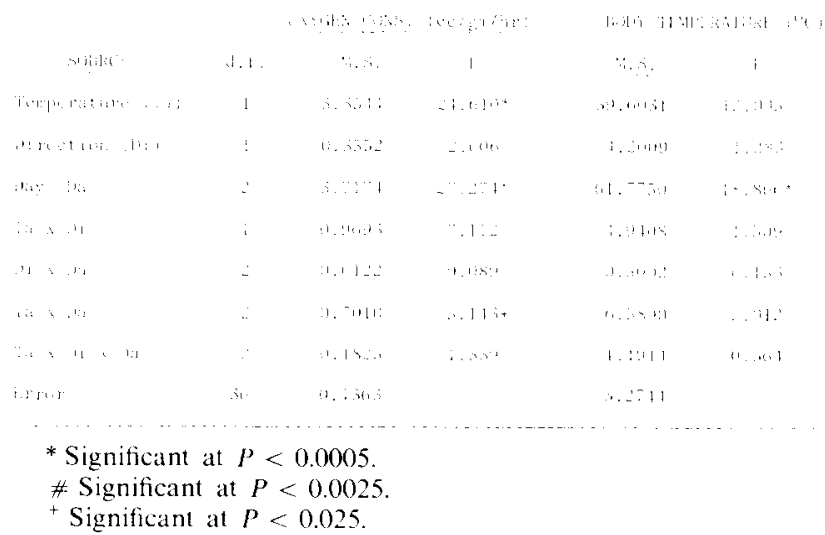




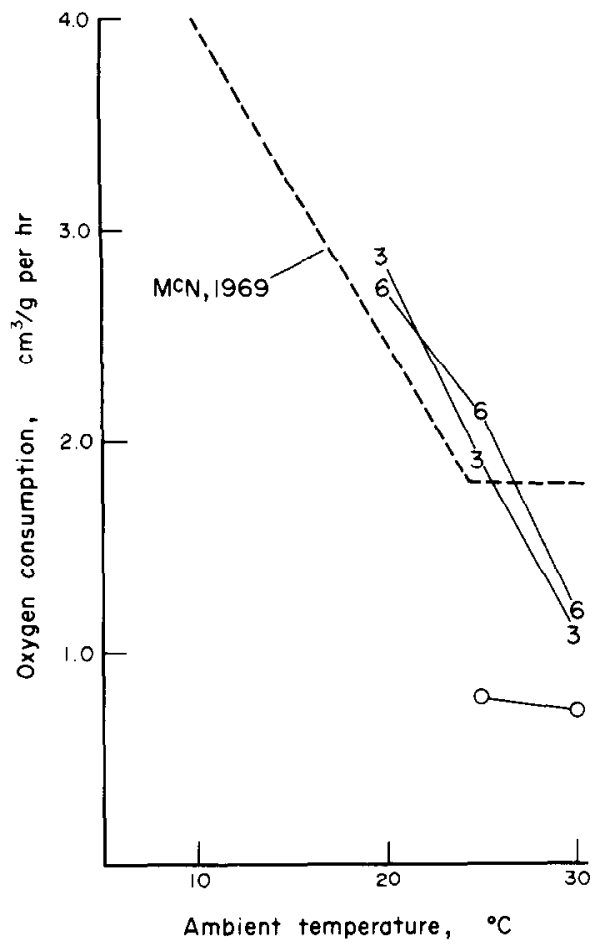

Fig. 2. The relationship of oxygen consumption to ambient temperature in Artibeus jamaicensis. Dashed line represents mean oxygen consumption found by McNab (1969). Mean oxygen consumption of bats tested after 0,3 and 6 days in captivity are shown.

regulatory performances in bats is acknowledged (see Studier \& O'Farrell, 1972). Time spent in captivity also should be recognized as a critical variable because bats tested immediately after capture are physiologically distinct from those tested after a short period of captivity.

Although the "captivity effect" describes the previously discussed divergent data on thermoregulation and metabolism in bats, it does not show which data set represents the natural thermoregulatory and metabolic activity of bats. Pertinent to this question are data reported by Studier \& O'Farrell (1972) for $M$. lucifugus and $M$. thysanodes. They found that the $T b$ s of these bats in their natural roosting sites were highly variable and similar to the data they presented for freshly caught, lab testcd individuals. It would appear then that data on bats tested soon after capture reflect the natural thermoregulatory performance of the species, whereas data on captive bats reflect the greatest homeothermic capabilities of the species.

Although no attempt was made to determine which components of the "captivity effect" are responsible, either singly or in combination, for the changeover in thermoregulatory performance, several probabililies exist. It is unlikely that the increased homeothermic response in this study results from thermal acclimation. No attempt was made to hold captive bats at constant $T a$, rather $T a$ for captive bats fluctuated in slightly muted fashion with natural environmental Ta. Furthermore, the "captivity effect" would not seem to be a general stress response since stress would probably be greatest during the initial hours in captivity and we thus would expect bats to be most accurately homeothermic on day 0 testing. The "captivity effect" may result from the individual or combined actions of reduced activity while caged or the continual presence of excess food, allowing the bats to eat at any time of day.

We theorize that in its natural environment, $A$. jamaicensis is a homeothermic endotherm during periods of feeding and flight activity, but loosens $T b$ control (becoming a non-homeothermic endotherm) during roosting (non-feeding, non-flying) periods. The slight reduction in $T b$ at such times would conserve large amounts of energy. In this situation a nonhomeothermic $A$. jamaicensis conserves 38.7 and $67.4 \%$ of the energy required of homeothermic individuals at $T$ as of 30 and $25 \mathrm{C}$, respectively. This would certainly amount to a major energy cost reduction over a half-day roosting period. We assume that the slight $T b$ reduction in $A$. jamaicensis ( $T b$ of $35.2^{\circ} \mathrm{C}$ at $T a$ of $30 \mathrm{C}$ and $T b$ of $32.5 \mathrm{C}$ at $T a$ of $25 \mathrm{C}$ ) would not reduce the responsiveness of individuals to environmental stimuli during roosting nor would it preclude flight initiation in this species.

The "captivity effect" described herein is the opposite of what one might expect. Animals that are good homeotherms may loose their ability to thermoregulate in captivity because of stress or poor nutritional state. Here we show that A. jamaicensis is a heterotherm when first captured, and quickly becomes homeothermic in captivity.

It is possible that thermoregulation is dependent on nutritional state in these animals. In the wild, $A$. jamaicensis feeds on fruit which varies seasonally in abundance from scarce to plentiful; individual bats may undergo a natural period of diel torpor, whereas animals kept with $a b$ lib food may never go torpid as long as the food supply is constant and plentiful. It would be interesting to see if imposing food stress on captive animals reverses the trend towards homeothermy shown here. Future studies directed towards the relationship between food availability, nutritional state, and thermoregulation in tropical bats might help explain why these animals show such variation in thermoregulatory response.

Acknowledgements- We thank Tracey K. Werner and Kate Wilson for field assistance and Richard W. Dapson for aid in statistical analysis. Michael A. Bogan, Richard W. Dapson, Charles O. Handley, Jr.. Steven R. Humphrey and Rrian K. McNab provided valuable comments on the manuscript.

\section{REFERENCES}

Gaertner R. A., Hart J. S. \& Roy O. Z. (1973) Seasonal spontaneous torpor in the white-footed mouse, Peromyscus leucopus. Comp. Biochem. Physiol. 45A, 169-181.

HiLl R. W. (1977) Body temperature in Wisconsin Peromyscus leucopus: a reexamination. Physiol. Zool. 50, 130-141.

MCNAB B. K. (1969) The economics of temperature regulation in neotropical bats. Comp. Biochem. Physiol. 31, 227-268.

SOKal R. R. \& Rohlf F. J. (1969) Biometry, 776 pp. W H. Freeman, San Francisco.

Stones R. C. \& Wiebers J. E. (1967) Temperature regulation in the little brown bat, Myotis lucifugus. In Mammalian Hibernation, Vol. 3 (Edited by FISCHER K. C.), pp. 97-109. Oliver \& Boyd-Elsevier, New York. 
Siunhr E. H. \& O'Farrel.l. M. J. (1972) Biology of

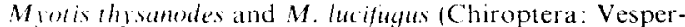
tilionidae) I. Thermoregulation. Comp. Biochem. Phl siol. 41 A, 567-595.
Studik E. H. \& Wussor D. E. (1970) Thermoregulation in sonc neotropical bats. Comp. Binchem. Phisiol 34. 251262 . 